Supporting Information For: es-2020-07507g-R2

\title{
Polychlorinated Naphthalenes Across the Great Lakes: Lake Trout and Walleye Concentrations, Trends, and TEQ Assessment - 2004-2018
}

\author{
James J. Pagano ${ }^{1, *}$, Andrew J. Garner ${ }^{1}$
}

${ }^{1}$ Environmental Research Center, Department of Chemistry, State University of New York at Oswego, Oswego, NY 13126

* Corresponding author

*E-mail: james.pagano@oswego.edu Phone: (315) 312-2810. Fax: (315) 312-5436 


\section{Table of Contents}

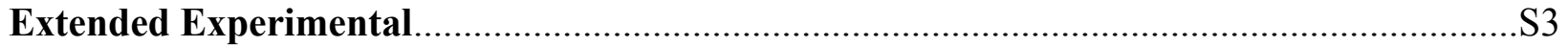

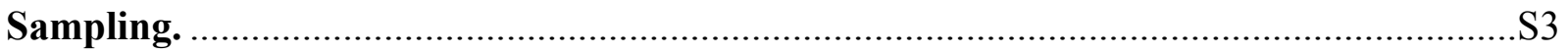

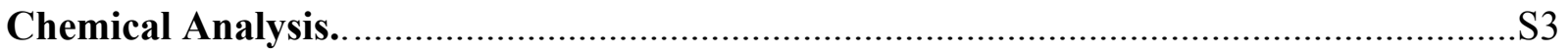

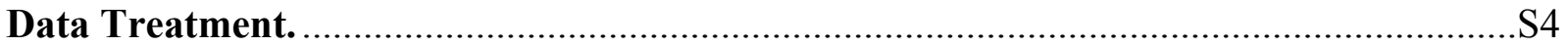

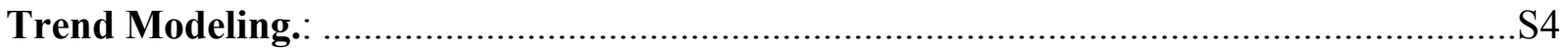

Figure S1. Map of odd-even year sampling sites for Great Lakes Fish Monitoring and

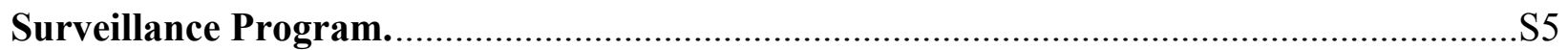

Figure S2. MEGA composite lake trout and walleye age trends for Lake Erie and Lake

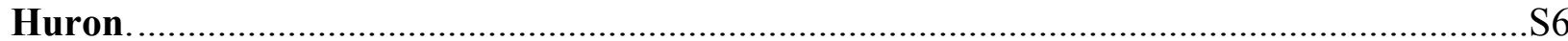

Figure S3. MEGA composite lake trout age trends for Lake Ontario, Lake Michigan, and

Lake Superior.

Figure S4. Average number of chlorines per naphthalene (AVG CI/CN) trends in Lakes Erie and Huron.

Figure S5. Average number of chlorines per naphthalene (AVG Cl/CN) trends in Lakes Ontario, Michigan and Superior..

Figure S6. Age Trend Models of total PCNs in the Great Lakes....................................S10

Figure S7. Age Trend Models of total TEQ in the Great Lakes. ....................................S11

Figure S8. Comparison of PCN_073 concentrations found in the Great Lakes................S12

Figure S9. Comparison of lake trout and walleye total TEQ ( $\sum$ PCDD/Fs + CP-PCBs + PCNs) concentrations in the Great Lakes basin (2004-2018)...

Table S1. Descriptive and model statistics and for average number of chlorines per naphthalene (AVG CI/CN) trends in the Great Lakes basin.

References: 


\section{Extended Experimental}

Sampling. Top predator fish (lake trout and walleye) from each Great Lake are alternately sampled annually from even-odd year collection sites. Top predator fish are collected and reflect the endpoint of contaminant bioaccumulation in the Great Lake food chain. Lake trout between 600-700 mm, or walleye (Lake Erie only) between 400-500 $\mathrm{mm}$ are sampled resulting in 10 composites of 5 fish each. Similar age fish are then sorted and homogenized together to form a composite. Equal amounts of the resulting 10 composites are then homogenized again to form a MEGA composite. These MEGA composites were then analyzed due to cost and time considerations. Overall, 123 samples were analyzed including QA samples (SI-WS-01 and 02).

Chemical Analysis. Sample cleanup and analytical procedures have been fully described elsewhere for PCNs ${ }^{1,2}$. Briefly, MEGA composite samples $(20 \mathrm{~g})$ were mixed with precleaned polyacrylic acid as a desiccant, spiked with labeled surrogates (Cambridge Isotope Laboratories, Tewksbury, MA). All samples were solvent extracted using an ASE 350 (Thermo Fisher Scientific, Waltham, MA) with methylene chloride. Prior to extraction, samples are spiked with ${ }^{13} \mathrm{C}_{12}$ labeled surrogate solution ECN-5490 (Cambridge Isotope Labs). Sample extracts were concentrated to $\sim 5 \mathrm{~mL}$ using a TurboVap II workstation (Biotage, Charlotte, NC), then solvent exchanged to hexane prior to cleanup using an FMS PowerPrep II Workstation (Fluid Management Systems, Watertown, MA). Method blanks (MB) and ongoing precision and recovery (OPR) samples were performed with each batch of samples. The ASE extraction sequences consisted of a method blank, 6-8 samples and an OPR sample. QA/QC was monitored by internal SOP laboratory measures and external QA review by General Dynamics Information Technology (Alexandria, VA). All QA metrics met or exceeded established USEPA-GLFMSP criteria and are provided as Supplementary Information (SI) Worksheet (WS)-01. Samples were analyzed by HRGC/HRMS using an Agilent 7890A gas chromatograph with a $60 \mathrm{~m}$ J\&W DB5-MS-UI column, Agilent 7893A autosampler, and Waters AutoSpec Premier mass spectrometer. Each sample was analyzed for 41 PCNs using a modified Method PCN-3431, respectively ${ }^{3-5}$. PCN calibration standards (ECN-5489, CS1-7) were obtained from Cambridge Isotope Labs. For all measurements, the mass spectrometric resolution was $>10,000$ and quantification was performed using isotope dilution techniques/criteria as specified in USEPA methodologies. The limit of detection (LOD), defined as 3 times RMS noise was generated by the Waters TargetLynx software using the instrument calibration curve. Method blanks (MB) and ongoing precision and recovery (OPR) samples were used with each batch of samples extracted on the ASE 350. Contaminant concentrations below the LOD are reported as zero. 
Data Treatment. All concentration data are presented on a wet-weight (ww) basis, to be consistent with other studies conducted in the Great Lakes. MEGA composite ages were calculated by averaging individual fish from each lake. Statistical analyses were performed using SigmaPlot version 13 software. Independent sample Mann-Whitney (M-W) U tests ${ }^{6}$ were used to determine differences in physical properties and contaminant concentrations between odd-even year collection sites within lakes to see if sites were significantly different and should be considered separately. The level of significance was set at $\mathrm{p}>0.05$. The Kruskal-Wallis $(\mathrm{K}-\mathrm{W})$ ANOVA on rank $^{7}$ was used to perform subgroup analysis. Parallel line tests for the equality of slopes $^{8}$ were conducted with SigmaPlot. Percent congener contribution to total PCNs was determined for 5 Aroclors $^{\mathrm{TM}}$ and 7 Halowax $^{\mathrm{TM}}$ technical mixtures. The PCN impurities in Aroclor $^{\mathrm{TM}}$ formulations were adapted from Yamashita et al (2000) by taking the ratio of the reported congener to total PCN concentrations and multiplying by 100 . The values in Halowaxes ${ }^{\mathrm{TM}}$ were calculated the same way from values reported in Noma et al. (2004).

TEQ values were calculated by the method outlined in Van den Berg in $2006^{9}$, as the sum of the products of concentrations of each individual compound multiplied by the associated TEF value ${ }^{10}$. The TEF values used to calculate TEQ values presented here are taken from Puzyn et al in $2007^{11}$, as they are used in recent studies in the Great Lakes and are directly comparable.

Trend Modeling. Trends were modeled using an Age-Trend Model (ATM) technique described by Pagano and coworkers. ${ }^{12}$ Briefly, the trends were modeled as two competing mechanisms: a linear model that describes the increase in concentration with age, followed by a first-order exponential decay of concentration over time. Equation 1 describes a linear increase in concentration with age:

$$
C_{A}=m A+\epsilon
$$

Where $\mathrm{C}_{\mathrm{A}}$ is the concentration at age $\mathrm{A}, \mathrm{m}$ is the slope and $\epsilon$ is an error term. This relationship is defined by modeling several individual composites over a wide variety of ages from a single lake. This relationship can then be used to calculate a concentration at a given age. Comparisons between individual composites collected in Lake Michigan in 2014 and the full age range of individuals collected in Lake Champlain were found not to be significantly different for total PCNs (SI WS 2). Given that the lake trout age range of Lake Michigan samples overlaps the age ranges of all the other Great Lakes, these samples were used to describe a combined linear uptake relationship for all lakes modeled. A separate age-concentration relationship was developed for Lake Erie walleye. Using this model assumes that the uptake dynamics found in Lake Michigan are functionally similar (slope is within the same magnitude and trend is in the same direction) for all lake trout in the Great Lakes. Previously, it has been demonstrated that the slope does not change significantly over long periods in a single lake and species. ${ }^{12}$ Additionally, a Rank Sum test comparing percent homolog contributions to total PCNs (SI WS 4) shows no significant differences between the Great Lakes over the sampling period, even when ages are significantly different. Additional samples from 2008, 2010 and 2012 were analyzed for the Lake Erie walleye age-concentration trend. Equation 2 describes a first-order exponential decay of the concentration over time: 


$$
C_{t}=C_{0} e^{-k t}
$$

Where $\mathrm{C}_{\mathrm{t}}$ is the raw concentration at time $\mathrm{t}, \mathrm{C}_{0}$ is the theoretical maximum concentration and $\mathrm{k}$ is the apparent elimination rate. The natural $\log$ of the ratio of the raw concentration to the predicted concentration at the MEGA composite age is then plotted as a function of time. General assumptions of the ATM have been previously reported. ${ }^{12}$

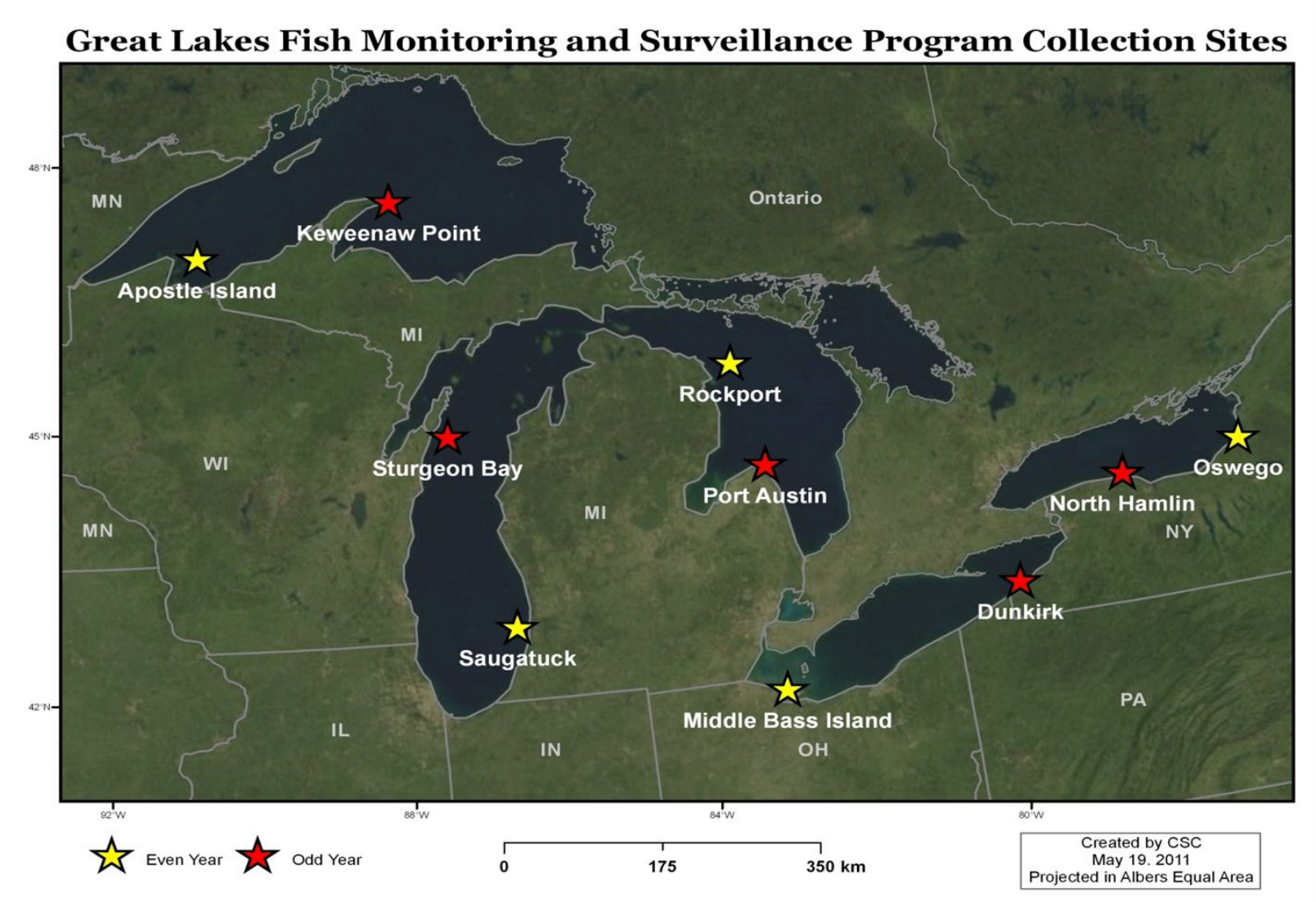

Figure S1. Map of odd-even year sampling sites for Great Lakes Fish Monitoring and Surveillance Program. 


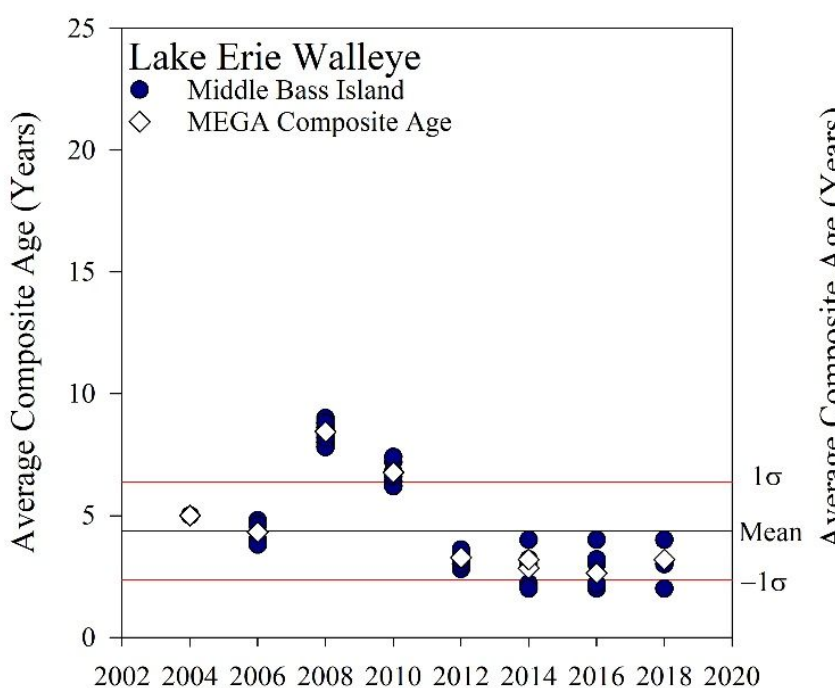

Collection Year

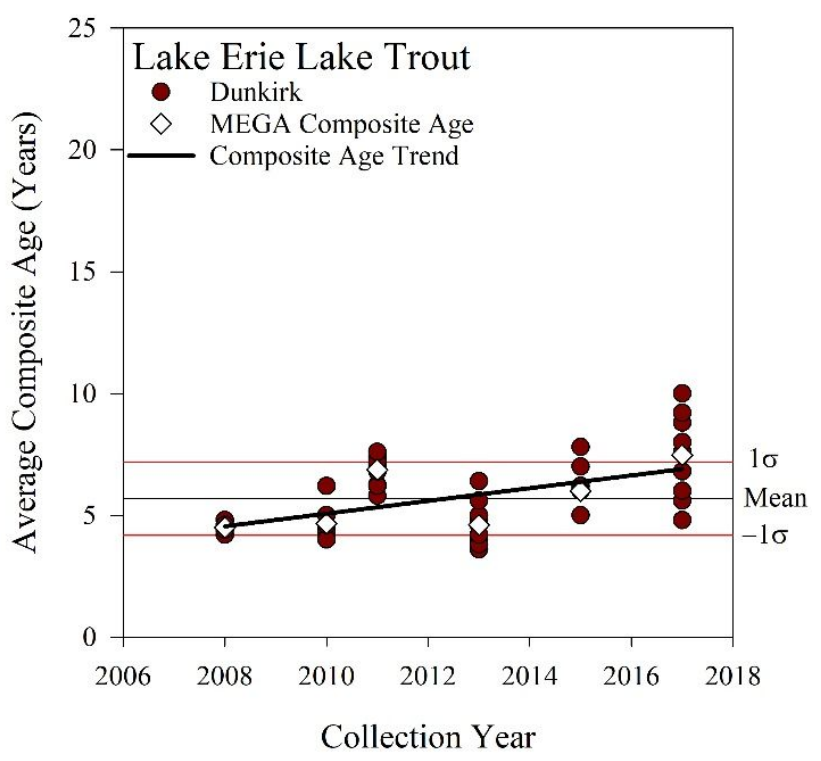

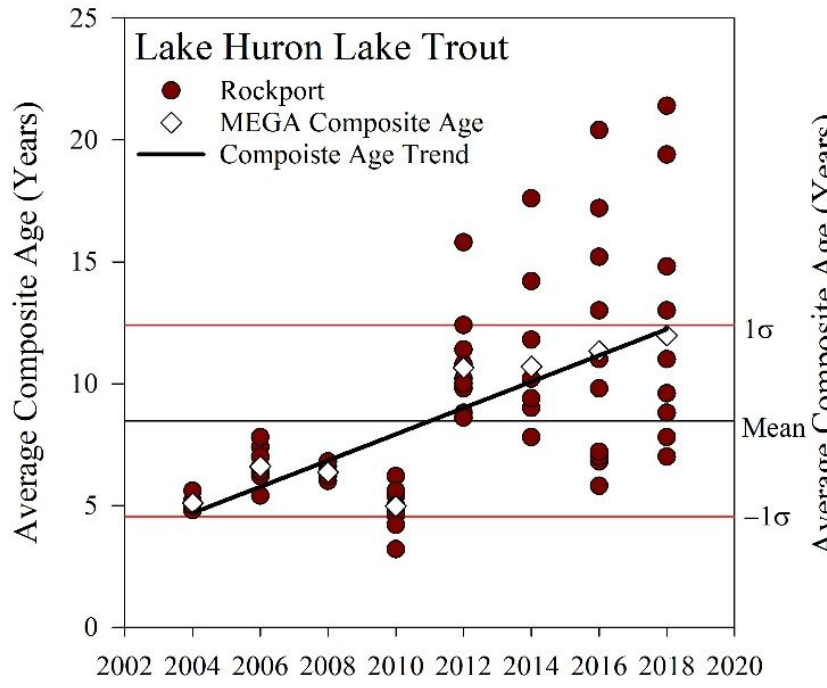

Collection Year

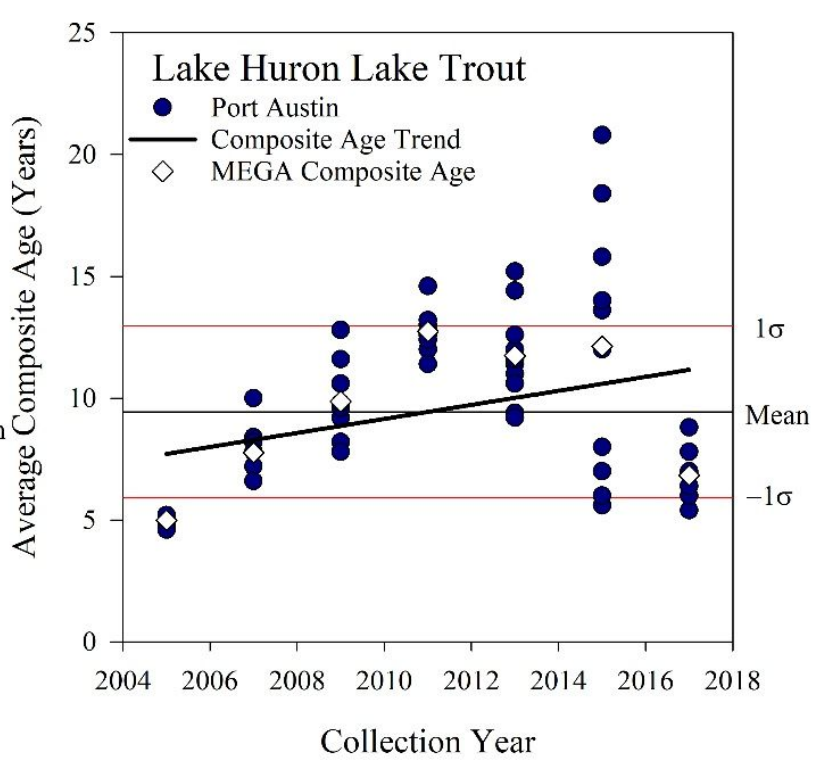

Collection Year

Figure S2. MEGA composite lake trout and walleye age trends for Lake Erie and Lake Huron. 


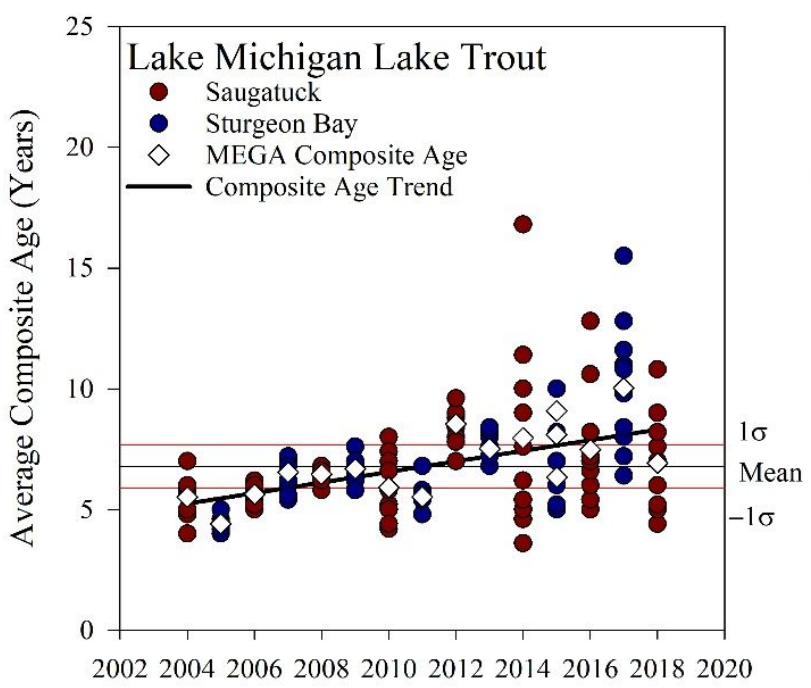

Collection Year

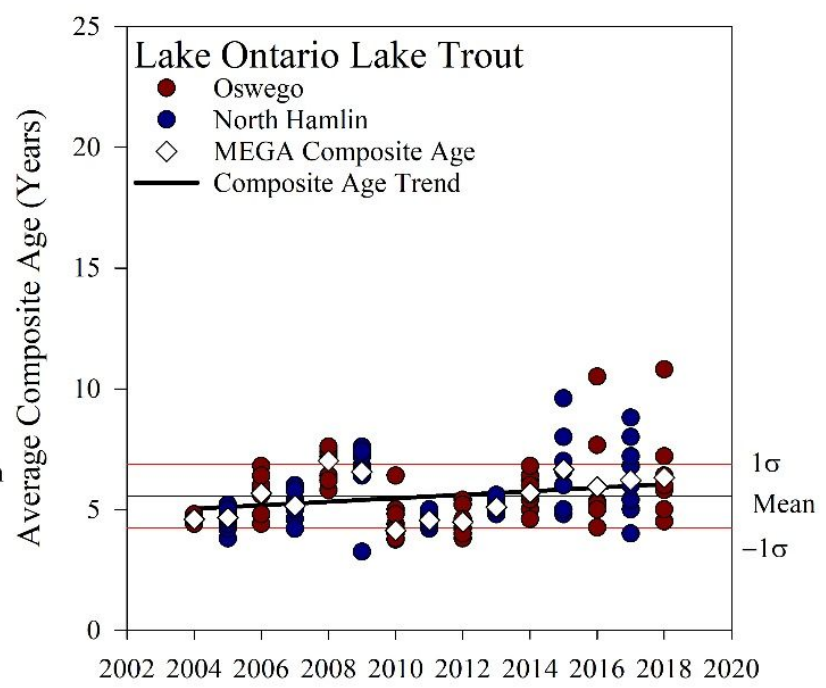

Collection Year

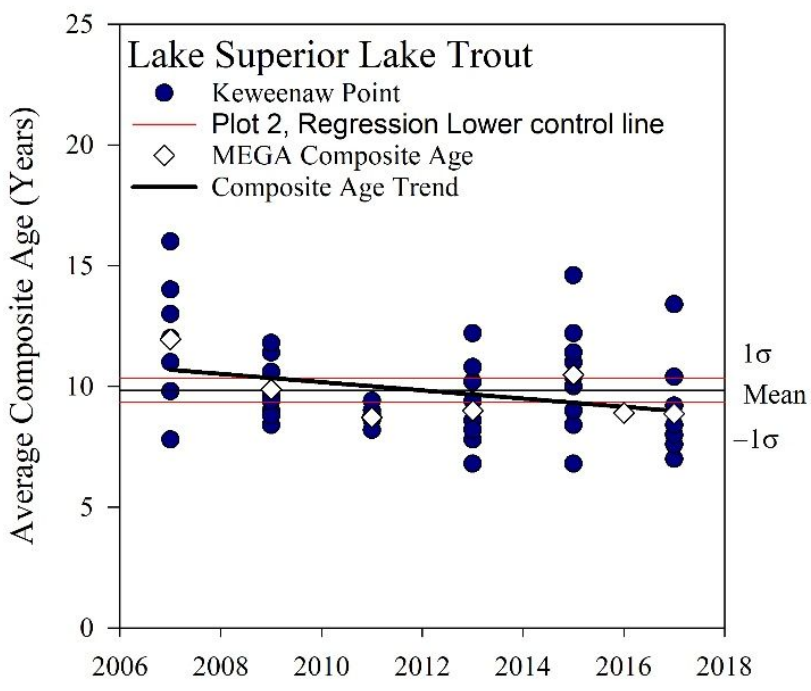

Collection Year

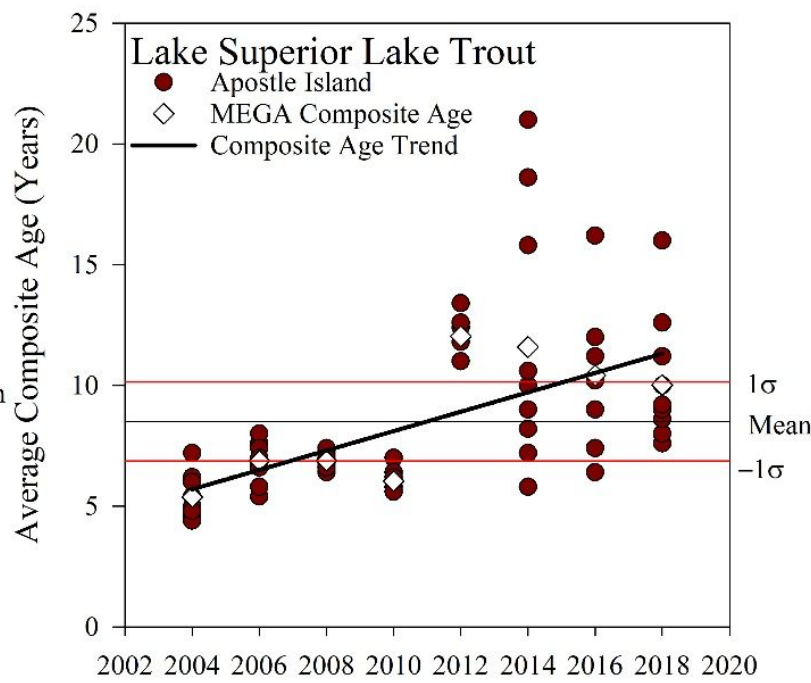

Collection Year

Figure S3. MEGA composite lake trout age trends for Lake Ontario, Lake Michigan, and Lake Superior. 

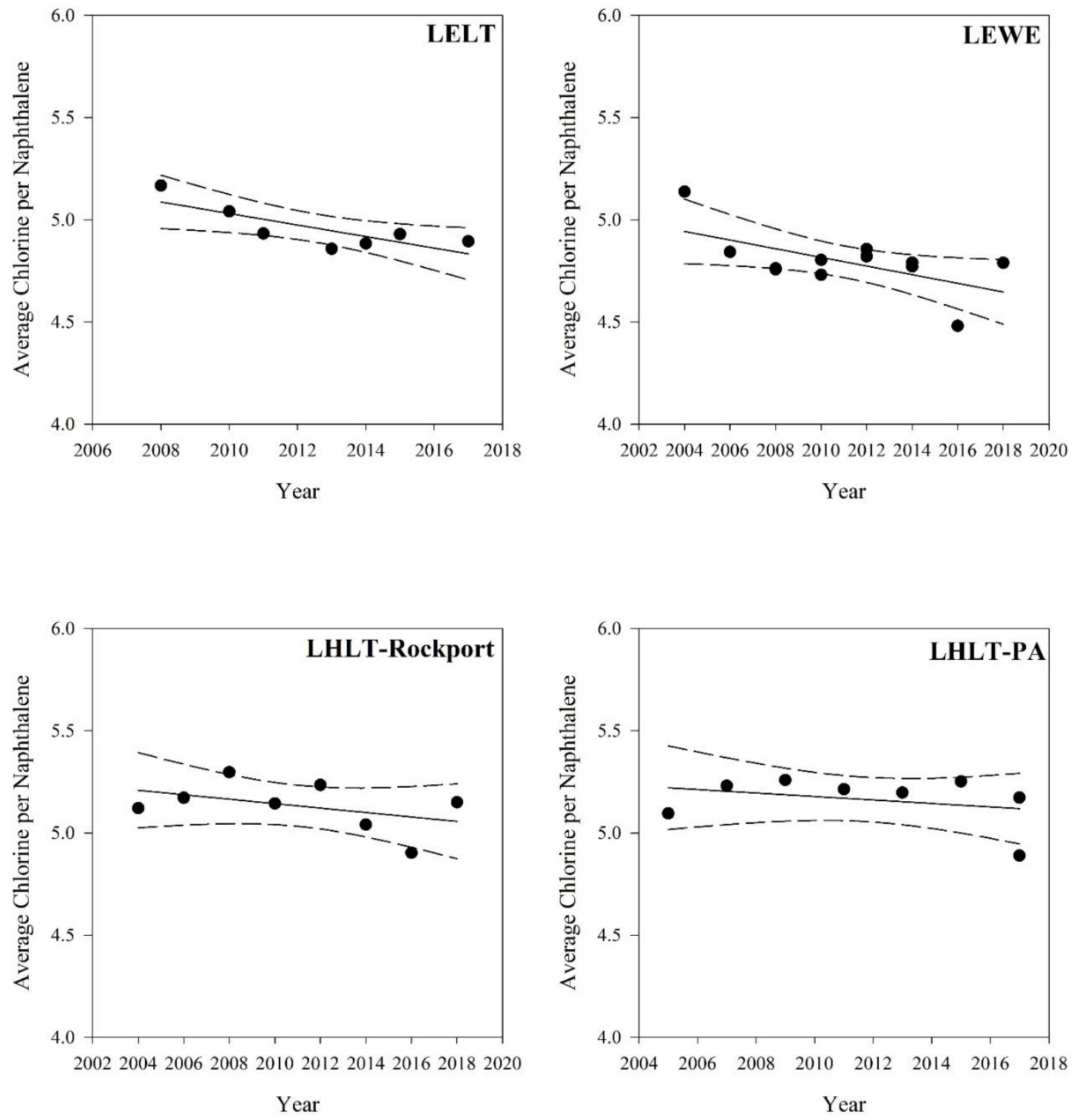

Figure S4. Average number of chlorines per naphthalene (AVG Cl/CN) trends in Lakes Erie and Huron. Model and descriptive statistics are reported in Table S-1. 

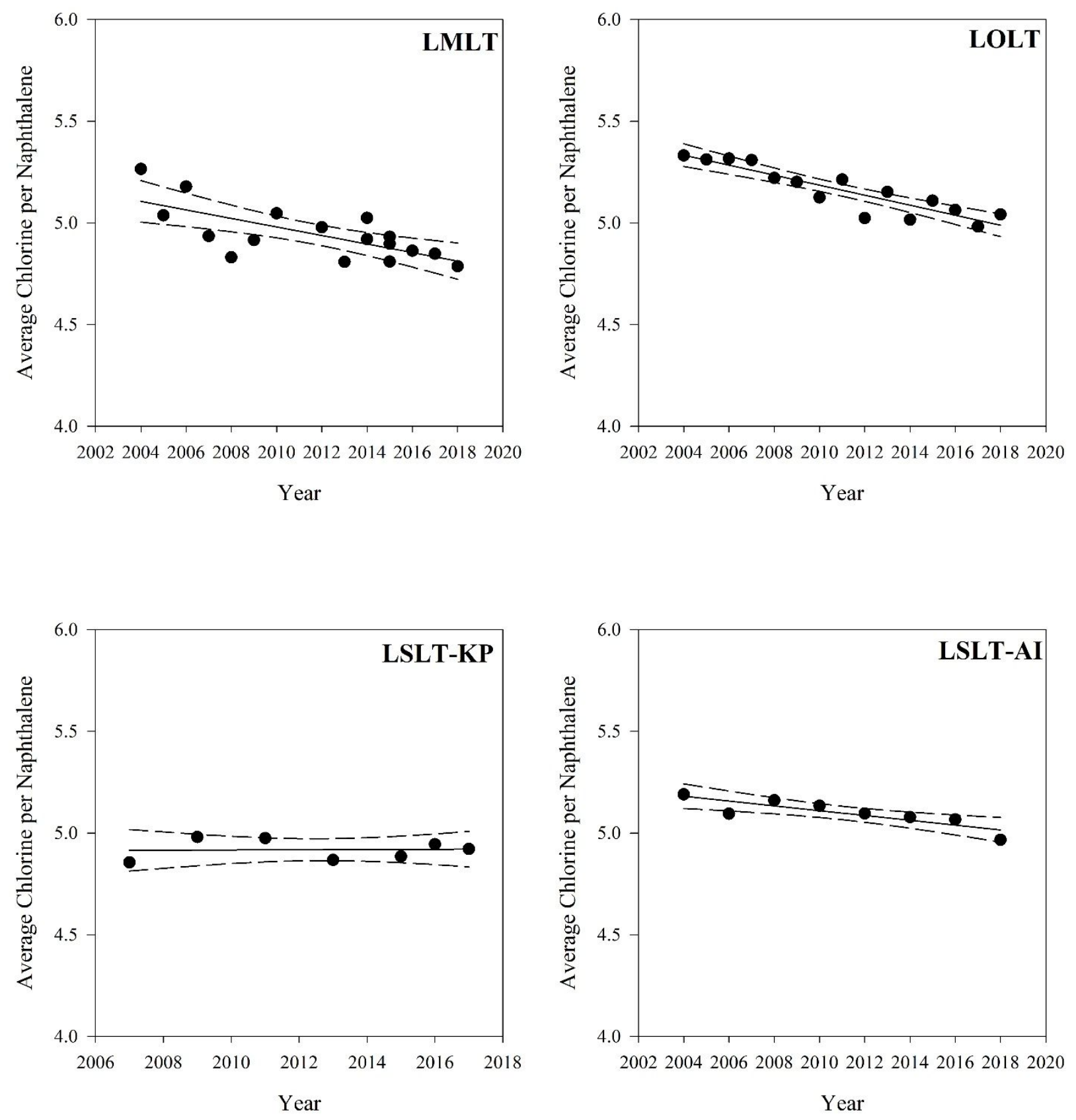

Figure S5. Average number of chlorines per naphthalene (AVG Cl/CN) trends in Lakes Ontario, Michigan and Superior. Model and descriptive statistics are reported in Table S1. 

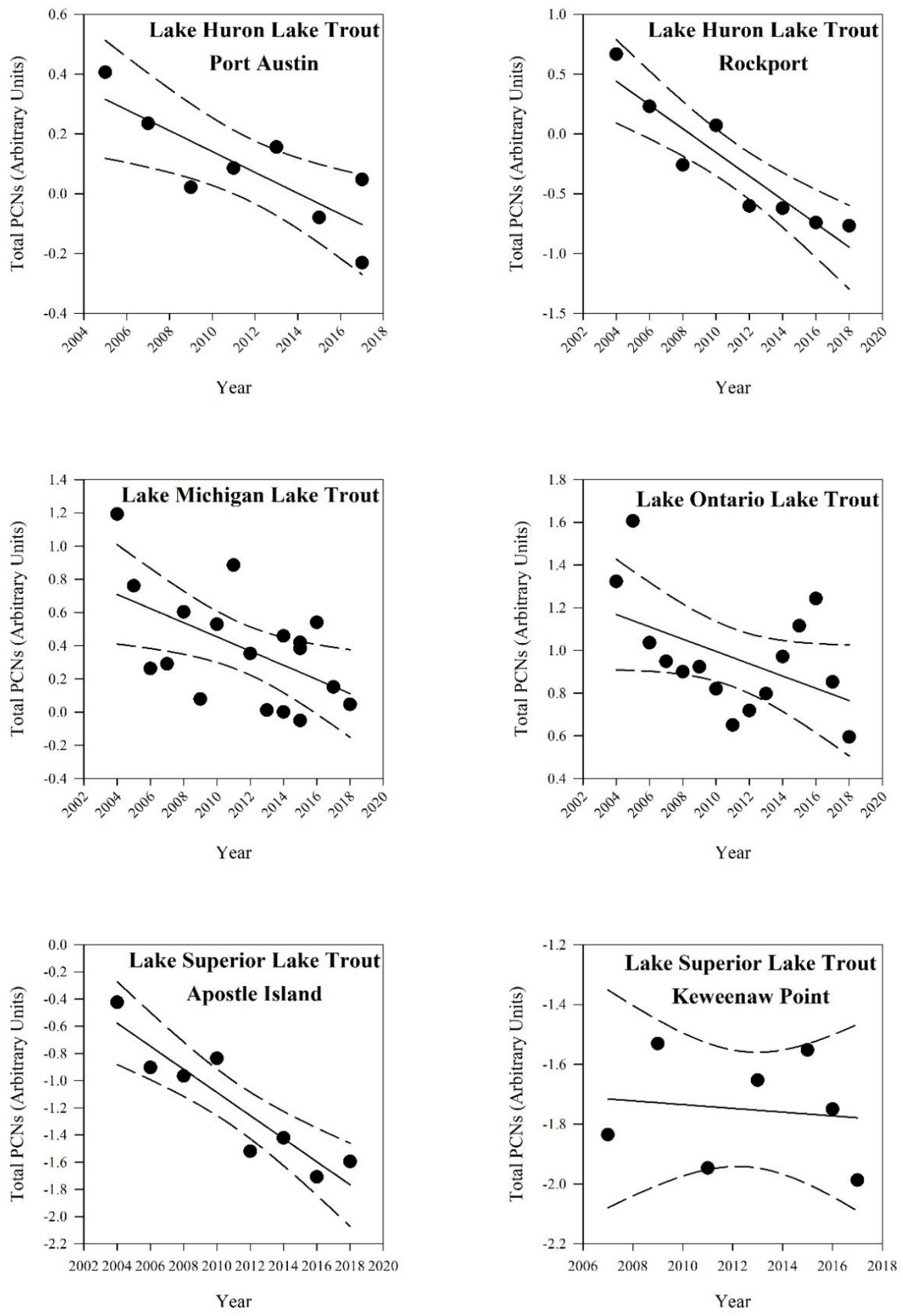

Figure S6. Age Trend Models of total PCNs in the Great Lakes. Model statistics are reported in Table 2. The y-axis is reported in arbitrary units, as the ATM model output is not a concentration. 

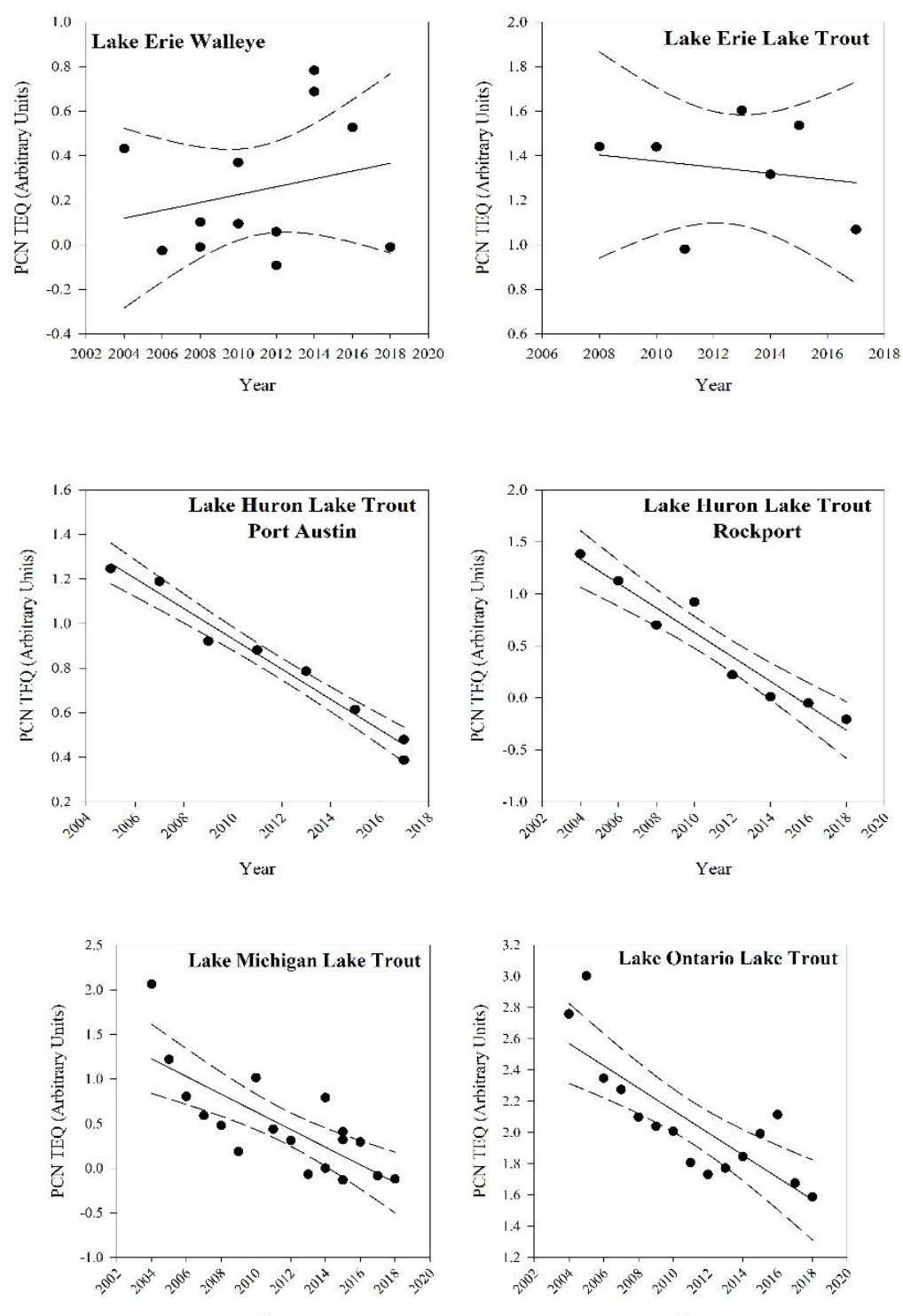

Year
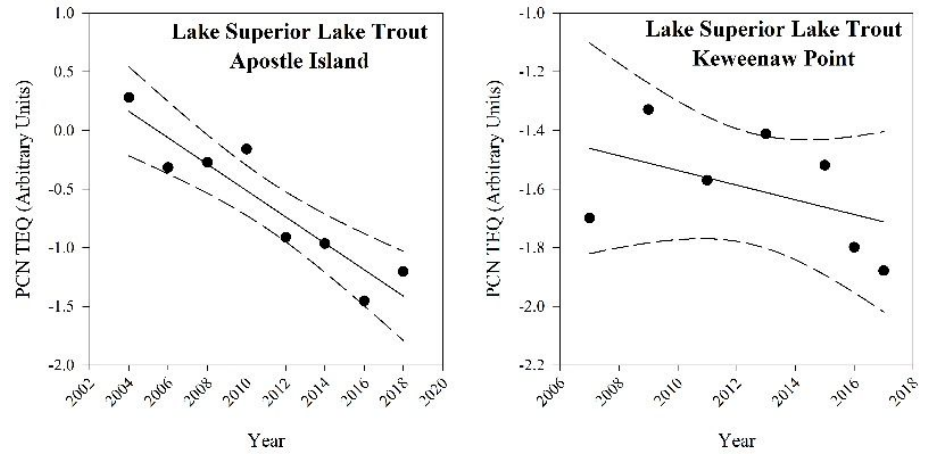

Figure S7. Age Trend Models of total TEQ in the Great Lakes. Model statistics are reported in Table 2. The y-axis is reported in arbitrary units, as the ATM model output is not a concentration. 


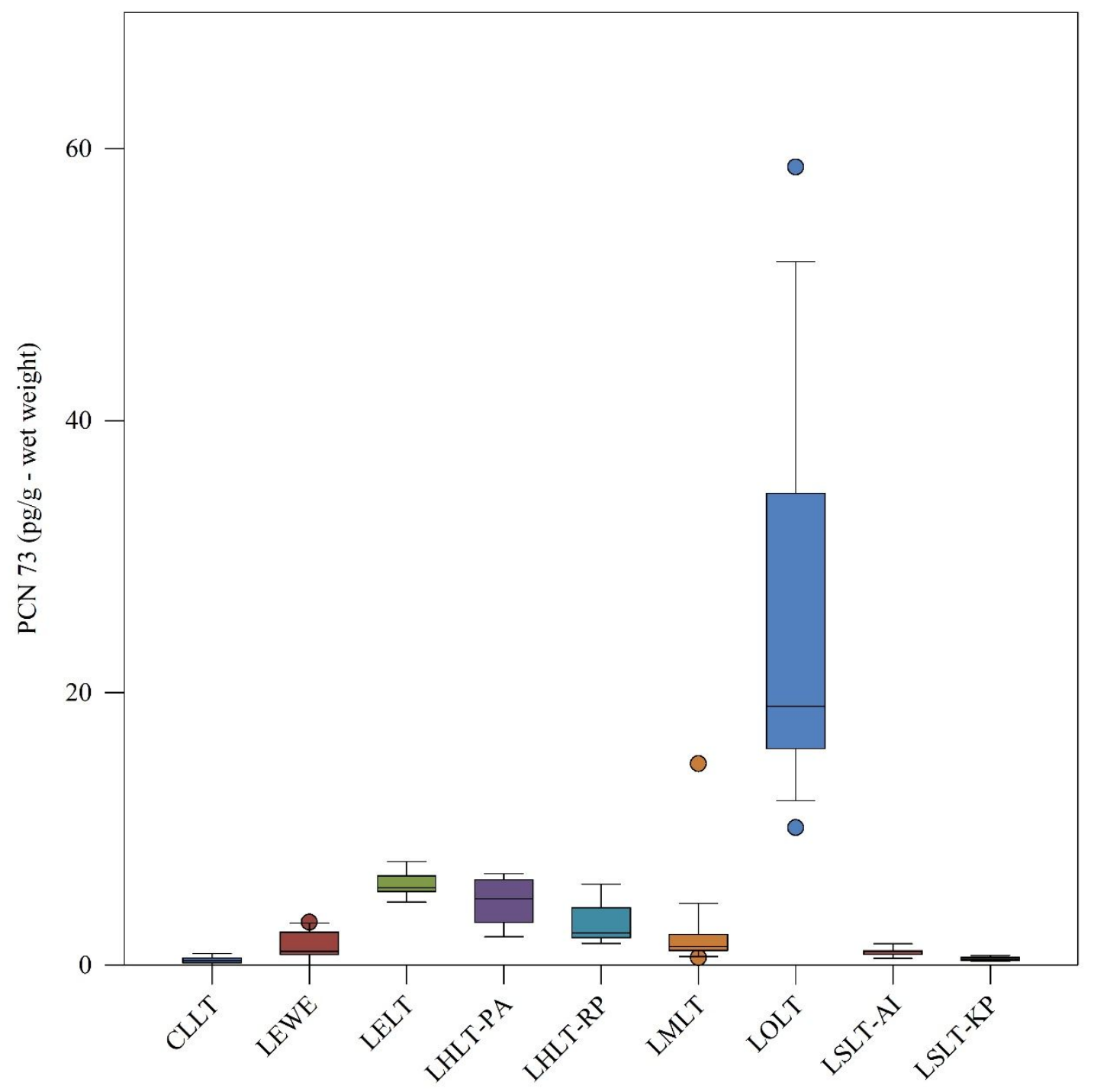

Figure S8. Comparison of PCN_073 concentrations found in the Great Lakes. The significant difference (rank sum test, $\mathbf{p}<0.001$ ) found in Lake Ontario PCN_073 concentrations may be attributed to PCN impurities found in Aroclor TM 1254 (SI WS-5). 


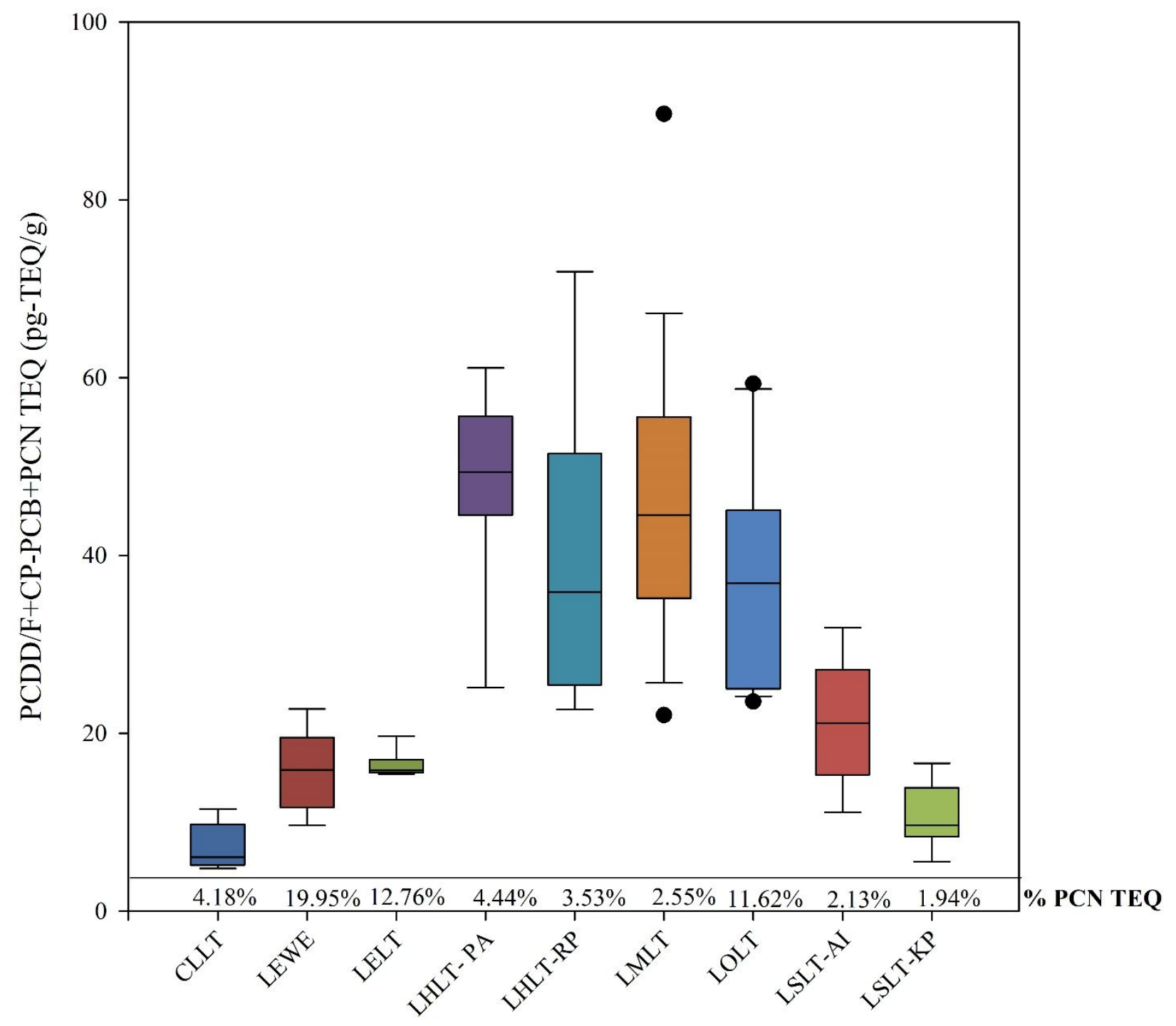

Figure S9. Comparison of lake trout and walleye total TEQ ( $\sum$ PCDD/Fs + CP-PCBs + PCNs) concentrations in the Great Lakes basin (2004-2018). Percentages of PCN TEQ to total TEQ are reported on the $\mathrm{x}$-axis. 
Table S1. Descriptive and model statistics and for average number of chlorines per naphthalene (AVG CI/CN) trends in the Great Lakes basin.

\begin{tabular}{|c|c|c|c|c|c|c|}
\hline & \multicolumn{2}{|c|}{ Average Chlorine per Naphthalene } & \multicolumn{3}{|c|}{ Trend } \\
\hline Lake & Mean & Max & Min & $\mathrm{r}^{2}$ & slope & $\mathrm{p}$ \\
\hline LEWE & 4.795 & 5.138 & 4.481 & 0.302 & -0.021 & 0.037 \\
\hline LELT & 4.959 & 5.167 & 4.859 & 0.571 & -0.028 & 0.030 \\
\hline LOLT & 5.161 & 5.332 & 4.982 & 0.810 & -0.025 & $<0.001$ \\
\hline LMLT & 4.946 & 5.265 & 4.787 & 0.462 & -0.021 & 0.002 \\
\hline LHLT-PA & 5.163 & 5.259 & 4.889 & 0.000 & -0.009 & $0.448^{*}$ \\
\hline LHLT-RP & 5.133 & 5.297 & 4.902 & 0.063 & -0.011 & $0.271^{*}$ \\
\hline LSLT-AI & 5.098 & 5.189 & 4.966 & 0.681 & -0.012 & 0.007 \\
\hline LSLT-KP & 4.918 & 4.980 & 4.855 & 0.000 & 0.001 & $0.934^{*}$ \\
\hline
\end{tabular}

\section{References:}

(1) Pagano, J. J.; Garner, A. J. Comprehensive Assessment of Legacy Organic Contaminants and Trends in Lake Trout from Cayuga Lake, New York: 2011-2017. Journal of Great Lakes Research 2019. https://doi.org/10.1016/j.jglr.2019.09.023.

(2) Pagano, J. J.; Garner, A. J. Concentrations, Toxic Equivalence, and Age-Corrected Trends of Legacy Organic Contaminants in Lake Champlain Lake Trout: 2012-2018. Environmental Research 2020, 109329. https://doi.org/10.1016/j.envres.2020.109329.

(3) Gewurtz, S. B.; Gandhi, N.; Drouillard, K. G.; Kolic, T.; MacPherson, K.; Reiner, E. J.; Bhavsar, S. P. Levels, Patterns, Trends and Significance of Polychlorinated Naphthalenes (PCNs) in Great Lakes Fish. Science of The Total Environment 2018, 624, 499-508. https://doi.org/10.1016/j.scitotenv.2017.11.332.

(4) McGoldrick, D. J.; Pelletier, M.; de Solla, S. R.; Marvin, C. H.; Martin, P. A. Legacy of Legacies: Chlorinated Naphthalenes in Lake Trout, Walleye, Herring Gull Eggs and Sediments from the Laurentian Great Lakes Indicate Possible Resuspension during Contaminated Sediment Remediation. Science of The Total Environment 2018, 634, 14241434. https://doi.org/10.1016/j.scitotenv.2018.04.077.

(5) Ontario Ministry of the Environment. The Determination of Polychlorinated Naphthalenes (PCNs) in Environmental Matrices by Gas Chromatography-High Resolution Mass Spectrometry (GC-HRMS); Laboratory Services Branch Method PCN-E3431; Ontario Ministry of the Environment: Toronto, Ontario, Canada, 2010.

(6) Mann, H. B.; Whitney, D. R. On a Test of Whether One of Two Random Variables Is Stochastically Larger than the Other. The Annals of Mathematical Statistics 1947, 18 (1), $50-60$. 
(7) Kruskal, W. H.; Wallis, W. A. Use of Ranks in One-Criterion Variance Analysis. Journal of the American Statistical Association 1952, 47 (260), 583-621. https://doi.org/10.2307/2280779.

(8) Schlechtriem, C.; Böhm, L.; Bebon, R.; Bruckert, H.-J.; Düring, R.-A. Fish Bioconcentration Studies with Column-Generated Analyte Concentrations of Highly Hydrophobic Organic Chemicals. Environ Toxicol Chem 2017, 36 (4), 906-916. https://doi.org/10.1002/etc.3635.

(9) Van den Berg, M.; Birnbaum, L. S.; Denison, M.; De Vito, M.; Farland, W.; Feeley, M.; Fiedler, H.; Hakansson, H.; Hanberg, A.; Haws, L.; Rose, M.; Safe, S.; Schrenk, D.; Tohyama, C.; Tritscher, A.; Tuomisto, J.; Tysklind, M.; Walker, N.; Peterson, R. E. The 2005 World Health Organization Reevaluation of Human and Mammalian Toxic Equivalency Factors for Dioxins and Dioxin-Like Compounds. Toxicological Sciences 2006, 93 (2), 223-241. https://doi.org/10.1093/toxsci/kfl055.

(10) USEPA. Recommended Toxicity Equivalence Factors (TEFs) for Human Health Risk Assessments of 2,3, 7,8-Tetrachlorodibenzo-p-Dioxin and Dioxin-like Compounds.; U.S. Environmental Protection Agency, Risk Assessment Forum: Washington, DC, 2010.

(11) Puzyn, T.; Falandysz, J.; Jones, P. D.; Giesy, J. P. Quantitative Structure-Activity Relationships for the Prediction of Relative in Vitro Potencies (REPs) for Chloronaphthalenes. Journal of Environmental Science and Health, Part A 2007, 42 (5), 573-590. https://doi.org/10.1080/10934520701244326.

(12) Pagano, J. J.; Garner, A. J.; McGoldrick, D. J.; Crimmins, B. S.; Hopke, P. K.; Milligan, M. S.; Holsen, T. M. Age-Corrected Trends and Toxic Equivalence of PCDD/F and CPPCBs in Lake Trout and Walleye from the Great Lakes: 2004-2014. Environ. Sci. Technol. 2018, 52 (2), 712-721. https://doi.org/10.1021/acs.est.7b05568. 